\title{
Analysis of Unsteady Flow Characteristics of Centrifugal Pump under Part Load Based on DDES Turbulence Model
}

\author{
Tang Xin, ${ }^{1}$ Liu Zhili, ${ }^{1}$ Zhao Meng, ${ }^{1}$ Yang Haotian, ${ }^{2}$ Jiang Wei $\mathbb{D D}^{1}{ }^{1}$ Wang Yuchuan, \\ and Chen Diyi ${ }^{1}$ \\ ${ }^{1}$ College of Water Resources and Architectural Engineering, Northwest A\&F University, Xianyang, Yangling 712100, China \\ ${ }^{2}$ College of Electrical and Power Engineering, Taiyuan University of Technology, TaiYuan 030024, China \\ Correspondence should be addressed to Jiang Wei; jiangweijt@nwafu.edu.cn
}

Received 15 March 2021; Revised 28 May 2021; Accepted 1 June 2021; Published 15 June 2021

Academic Editor: Yong Zhu

Copyright (c) 2021 Tang Xin et al. This is an open access article distributed under the Creative Commons Attribution License, which permits unrestricted use, distribution, and reproduction in any medium, provided the original work is properly cited.

\begin{abstract}
To better reveal the mechanism of the rotor-stator interference between the impeller and the guide vane and the evolution process of the stall vortex under the part-load conditions, numerical simulation is carried out based on the DDES turbulence model, which can better capture vortex structure. And the pressure pulsation and the radial velocity distribution of the centrifugal pump are studied. The vortex structure and pressure fluctuation of pump internal flow field under part-load condition of $Q=0.4 Q$ des are mainly analyzed. The analysis results show that the stall vortex is formed at the inlet of the impeller and evolves to the outlet of the impeller, the front cover to the rear cover according to the fluid flow direction, and then disappears. Besides, under the part-load condition, the vorticity of the impeller outlet is always obviously less than that of the impeller inlet as the flow rate increases. Due to the asymmetric action of the volute, the radial velocity distribution law of flow channel C1 is different from other flow channels at different blade heights. By analyzing the radial velocity, the phenomenon that the jet-wake flow impacts the guide vane with the rotation of the impeller is the main reason for the rotor-stator interference. And large radial velocity gradients appear at the front and rear cover plates, which will cause high energy loss and reduce pump efficiency. Besides, the conclusion can be drawn that the region with the strongest rotor-stator interference is the inlet region of the guide vane suction surface. It also occurs near the volute tongue but is lower due to the effect of the guide vane. This research may serve as a reference for the safe operation of centrifugal pumps under part-load conditions.
\end{abstract}

\section{Introduction}

Nowadays, with the development of science and technology, the pump, especially the centrifugal pump, has been an indispensable power machine everywhere we can see, applied widely in agriculture, aerospace, water conservancy engineering, nuclear industries, and medical treatment [1-3]. In this era background, more and more scholars at home and abroad focus on the experiment and research of centrifugal pumps. Zou et al. [4], Li et al. [5], and Yun et al. [6] all researched with the centrifugal pump during the startup process, obtaining the evolution features of the internal flow field and analyzing some fluid phenomena, which can provide some reference for the research of prototype pump's startup period. As a mechanical device of energy conversion and fluid transportation, rotor-stator interaction (RSI) is the main factor of vibration and noise in a centrifugal pump. And the degree of noise and vibration of the pump is one of the important indicators that reflect whether it is operating normally. Based on Lighthill acoustic analogy theory, Si et al. [7] concluded that the dipoles can be used to reflect the radiant noise of multistage centrifugal pump and its dominant frequency is the passing frequency of blades (BPF), which proved that rotor-stator interaction is the main noise source. To reduce the noise of centrifugal pumps, Liu et al. [8] and Dai et al. [9] performed both numerical simulation and experiments to test how much the performance of the pump can improve by using different bionic structures. With the widespread application of pump, its medium is no longer just a single fluid, but two or even three 
phases, such as gas-liquid/solid-liquid two-phase flow, which have large deference in internal flow and external characteristics of centrifugal pump comparing with singlephase flow $[10,11]$.

RSI is a classical physical phenomenon of blade-type rotating machinery, which has an important impact on the operation stability and security of rotating parts. As a typical and widely used rotating machinery, the RSI of the centrifugal pump when operating becomes a more and more popular research issue. At present, numerical simulation and experiments are dominant research approaches of RSI, mainly revealing the flow field structure and the pressure pulsation characteristics by time-frequency domain analysis. Cao et al. and Rodriguez et al. $[12,13]$ proceed research to capture the unstable flow properties and the pressure pulsation features induced by RSI between the guide vanes and impeller of centrifugal pump, obtaining the conclusion that the dominant frequency of pressure pulsation is roughly consistent with the blade passing frequency and the number of peaks and valleys of pressure pulsation curve is coincident with blades. Also, Issa et al. [14] explored the influence of the RSI on the steady and unsteady radial force in a centrifugation between impeller blade and volute tongue. And the curves of the experiment and numerical ones have a good agreement. Apart from the centrifugal pump, Li et al. [15] advanced research based on the diameter mode theory to analyze the RSI in turbine model of a pump-turbine model, indicating the change rule of the vaneless region.

In recent decades, more and more investigators focus on the research of stall vortex, which is a typical phenomenon that resulted from flow separation in blade tip region link to sudden drop of flow velocity. To explore its formation mechanism, most studies pay attention to the field of compressors, axial flow pumps, and mixed flow pumps [16-19]. To better capture the vortex structure and obtain more superior flow field information, many scholars have introduced the DDES turbulence model into the numerical simulation analysis of rotating machinery, which is the relatively accurate turbulence model at present [20-22]. But at present, this method is applied more in compressors and less in pumps [23-26]. Hence, the dominant work of this paper is to carry out the DDES analysis of flow field at the off-design condition of a centrifugal pump and reveal the mechanism of RSI and the formation mechanism of stall vortex, which can provide some reference for reduction of pressure pulsation and improvement of internal flow field and efficiency.

\section{Numerical Setup}

2.1. Basic Parameters of Centrifugal Pump. In this paper, the centrifugal pump is mainly composed of an inlet, impeller, guide vane, volute, and outlet. The basic parameters of the design condition are as follows: the design flow rate $Q_{\text {des }}=40 \mathrm{~m}^{3} / \mathrm{h}$, the design head $H=60 \mathrm{~m}$, and the rotating speed $n=2900 \mathrm{rpm}$. The basic parameters of the impeller are as follows: outlet diameter $D 1=223 \mathrm{~mm}$, outlet width $b 1=8 \mathrm{~mm}$, and blade number $Z 1=6$. The basic parameters of guide vane are as follows: inlet diameter $D 2=228 \mathrm{~mm}$, outlet diameter $D 3=283$, blade width $b 3=10 \mathrm{~mm}$, and blade number $Z 2=5$. The basic parameters of volute are as follows: base diameter $D 4=284$ and inlet width $b 4=19 \mathrm{~mm}$. To make sure of the accuracy of the experiment results, the pump body and impeller are made of organic glass and guide vane is using PVC. Figure 1 shows the experimental model of the pump.

2.2. Numerical Model. 3D model of an experimental centrifugal pump is carried out through ProE. The numerical calculation grid of the 3D model is divided by ICEM hexahedral structured grid. The result of mesh division is shown in Figure 2. To ensure accurate calculation of wall flow, the grid around the wall should be encrypted, and the average $Y_{+}$should be below 100. The value of boundary layer $y+$ does not exceed 100. Figure 3 presents the distribution of $Y+$ of the centrifugal pump. The ANSYS CFX numerical simulation software is applied to the model calculation. The DDES turbulence model is applied in this paper. Static pressure is adopted as an inlet boundary condition, and the mass flow rate is set as an outlet boundary condition. No-slip walls are adopted to all walls. Stable simulation is used as the initial calculation condition of transient simulation. The time step is set as $5.75 \times 10^{-5} \mathrm{~s}$, which is described as $1^{\circ}$ rotation of the impeller. A calculation cycle is 360 steps; a total of 10 cycles are calculated.

To make full use of calculation resources and ensure the accuracy of calculation results, the grid independence verification is carried out. Under the design condition, head and efficiency of centrifugal pump are 59.4 and $71.8 \%$ separately. In this paper, there are four schemes of grid division presented; the result of grid independence verification is displayed in Table 1. As shown in Table 1, the head and efficiency of this centrifugal pump no longer increase when the grid number is greater than the third scheme, and the errors of scheme 3 and scheme 4 are both lower than 0.02 . Therefore, the third set of grid numbers is selected as a mesh of numerical simulation, considering the time and cost of calculation.

2.3. Experiment Validation. To ensure the result of numerical simulation can be employed to analyze the internal flow field of centrifugal pump, the external characteristic outcomes of numerical simulation and experiment are compared, which is presented in Figure 4. According to the figure, the trend of curves is consistent with an overall error within $5.8 \%$. And under the design condition $\left(Q=40 \mathrm{~m}^{3} / \mathrm{h}\right)$, the results of error of head and efficiency are $5.7 \%$ and $2.2 \%$, respectively. When this centrifugal pump operates with a flow rate greater than $0.4 Q_{\mathrm{des}}$, this illustrates that the numerical simulation results have certain credibility and can be utilized to analyze the flow field of the centrifugal pump.

\section{Result and Discussions}

Figure 5 presents the structure of the centrifugal pump. In this article, the guide vanes are named $b 1, b 2, \ldots, b 5$ in the counterclockwise direction. With the same naming rule, the 


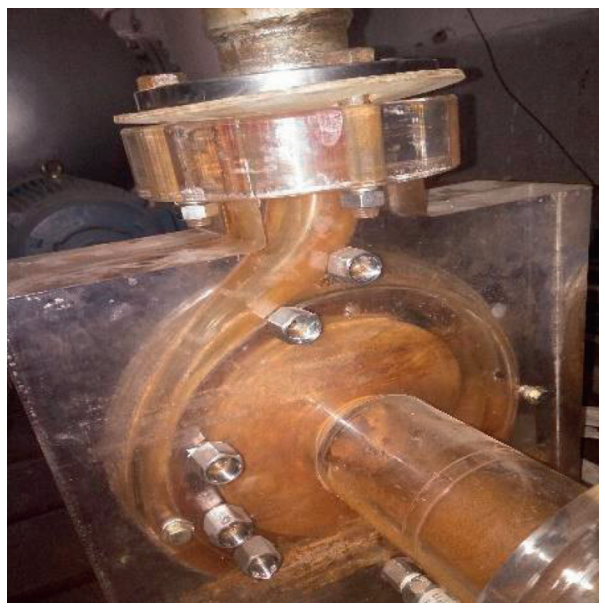

FigURE 1: Experimental model of the centrifugal pump.

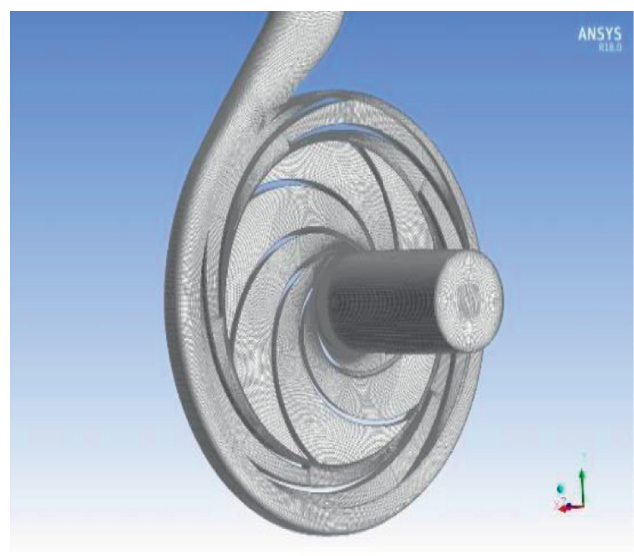

(a)

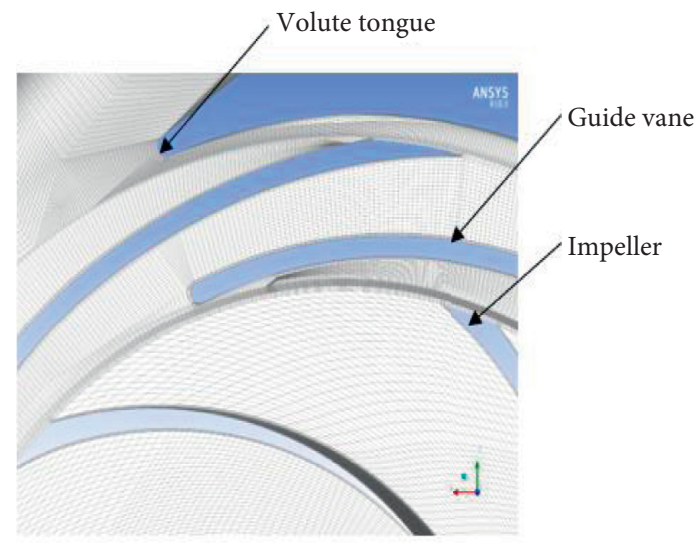

(b)

Figure 2: Mesh of the computational domain.

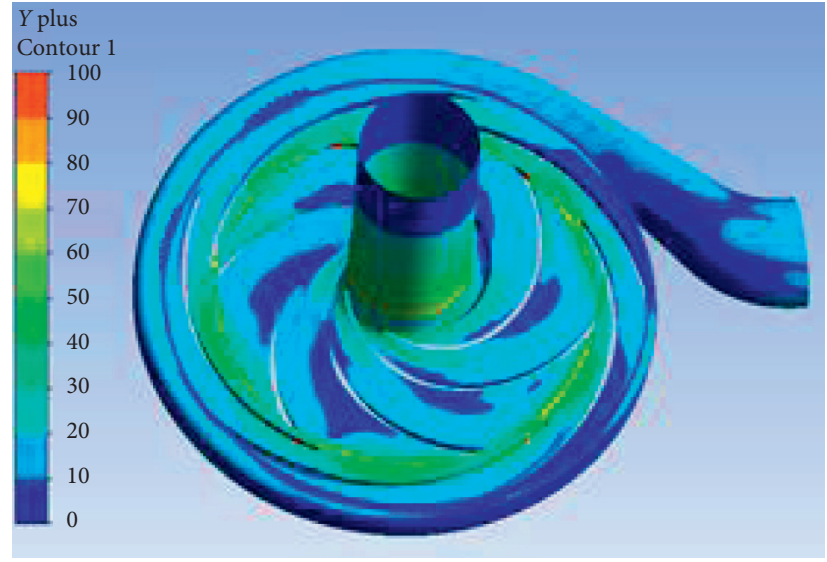

FIGURE 3: Distribution of $Y+$ of the centrifugal pump.

flow channels between adjacent blades of guide vane are named as $c 1, c 2, \ldots, c 5$ in turn, and the flow channels between adjacent blades of the impeller are named as $C 1, C 2$, ..., $C 5$ in turn.
Figure 6 illustrates the vortex distribution in the middle section of the impeller under different working conditions. A large number of vortices appear in the flow passage of the impeller, which decreases as flow increases. This is due to the 
TABLE 1: Verification of grid independence.

\begin{tabular}{lccccc}
\hline Scheme & Grid number $\left(10^{6}\right)$ & $H$ & $H$-error & $\eta$ & $\eta$-error \\
\hline 1 & 1.22 & 63.41 & 0.07 & -0.05 \\
2 & 1.54 & 62.12 & 0.04 & 69.54 & -0.03 \\
3 & 2.21 & 60.76 & 0.02 & 72.56 & 0.01 \\
4 & 2.44 & 60.53 & 0.02 & 72.90 & 0.01 \\
\hline
\end{tabular}



FIgURE 4: Comparison of the hydraulic performance between the numerical and test results.

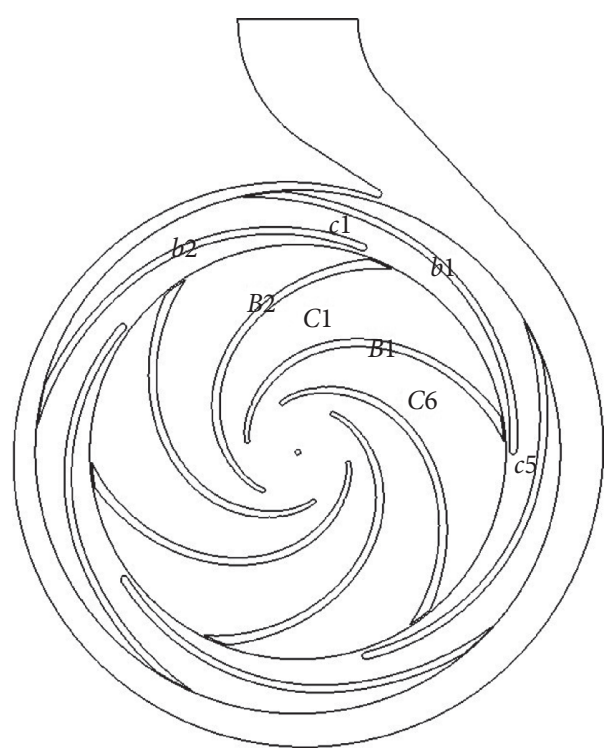

FIgURE 5: Structure of the centrifugal pump. 

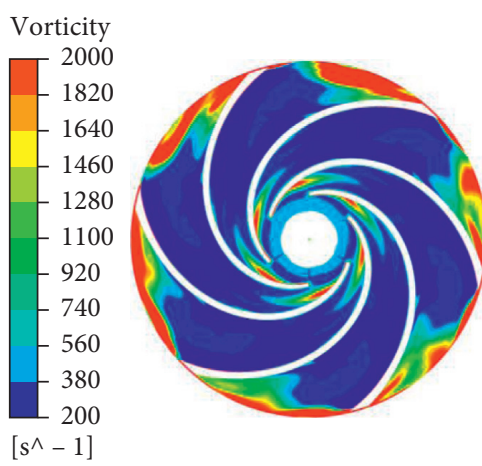

(a)
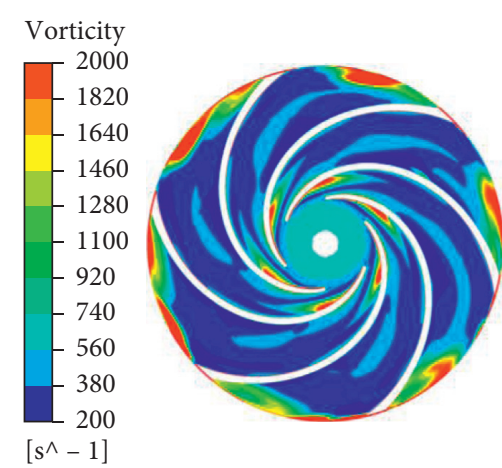

(b)
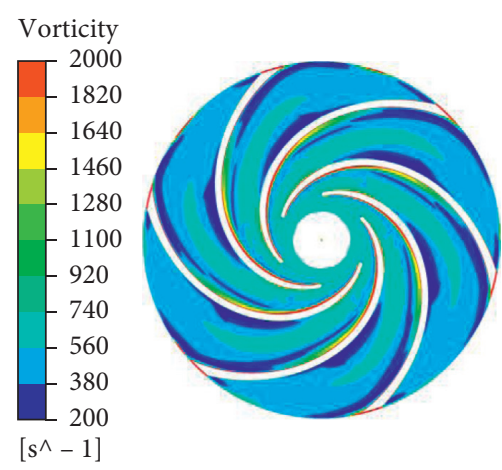

(c)

Figure 6: The vortex distribution in the middle section of impeller under different working conditions. (a) $Q=0.4 Q_{d}$. (b) $Q=0.6 Q_{d}$. (c) $Q=Q_{d}$.

large difference between the fluid flow angle at the impeller inlet and the placement angle of the impeller blades under small flow conditions, causing the fluid to flow around the leading edge of the blade, reducing the flow velocity near the suction surface, and separating the boundary layer of the suction surface, thereby forming a large amount of vortex. When the flow rate is too low, it is easy to form a vortex at the inlet of the impeller, causing a rotating stall phenomenon. While the flow rate adds up to $0.6 Q_{\mathrm{des}}$, the boundary layer separation point moves slightly downstream, but the amount of stall vortices do not significantly reduce, and the vorticity at the inlet of the impeller is significantly less than that at the outlet of the impeller. The main reason is that the downstream channel is wider than the impeller inlet channel, and the blocking ability of the vortex flow channel is poor. Thus, the vorticity of the impeller outlet in the condition of $0.6 Q_{\text {des }}$ is lower than $0.4 Q_{\text {des. }}$. Under the $Q_{\text {des }}$ condition of the impeller channel, the stall vortex at the impeller inlet and outlet all disappear, and the vorticity in the whole impeller is less than $1000 \mathrm{~s}^{-1}$. It illustrates that the stall vortex generated by the rotating stall has a significant impact on the downstream flow structure.

To reveal the evolution of stall vortex and its influence on downstream flow structure, the $Q$ criterion, widely used vortex identification, is applied to identify the vortex band at impeller inlet. The $Q$ criterion is based on the decomposition of the local velocity gradient tensor $D_{i j}, D_{i j}=S_{i j}+w_{i j}, S_{i j}$ is a symmetric tensor, and $w_{i j}$ is an antisymmetric tensor, representing the deformation and rotation parts of the fluid, respectively. The characteristic equation can be described as $\lambda^{3}+P \lambda^{2}+Q \lambda+R=0$, where $P, Q$, and $R$ are invariants of velocity tensor gradient. $Q$ is defined as

$$
\begin{aligned}
Q & =\frac{1}{2}\left[\operatorname{tr}(\bar{D})^{2} \cdot \operatorname{tr}\left(\bar{D}^{2}\right)\right], \\
& =\frac{1}{2}\left(\left\|\omega_{i j}\right\|^{2} \cdot\left\|S_{i j}\right\|^{2}\right) .
\end{aligned}
$$

Figure 7 presents vortex structure comparison of impeller inlet at different times in the condition of $0.4 Q_{d}$. As is shown, complex vortex structure and high turbulent kinetic energy appear at the inlet of the impeller passage, which is caused by rotating stalls at a low flow rate. Due to the uneven distribution of stall vortex at impeller inlet, stall vortices near the front cover are more than near the back cover. The stall vortex is initially caused by the boundary layer shedding at the front edge of the impeller blade suction. Most of it evolves downstream along the blade pressure side, and a small part flows downstream along the blade suction surface. There is no obvious stall vortex cluster near the rear cover plate of the impeller, which indicates that the impeller inlet near the front cover plate is affected by the vortex under partial flow conditions. The flow channel is blocked, leading to a poor flow capacity, and there is no vortex near the front cover plate, leading to a strong flow capacity. Besides, since the flow passage is not completely blocked by the vortex, there is almost no difference in the distribution of the vortex in the impeller flow passage at different times.

To study the distribution of vortex at different blade heights and its impact on the downstream flow field, Figure 8 depicts the distribution of vorticity and velocity vector. It can be seen that when approaching the front cover plate, a large area of vorticity greater than $2000 \mathrm{~s}^{-1}$ appears at the inlet of the flow channel, and the area where the vorticity of the middle cross section of the impeller is greater than $2000 \mathrm{~s}^{-1}$ moves into the flow channel, and the area is smaller. Meanwhile, the area near the rear cover with a vortex greater than $2000 \mathrm{~s}^{-1}$ is more inclined to the inside of the flow channel, and the area becomes smaller. This phenomenon illustrates that the stall vortex of the impeller inlet evolves from the impeller inlet to the impeller outlet, from the front cover to the rear cover, and finally disappears. From the velocity vector diagram, the stall vortex cluster has a significant impact on the downstream flow structure during the evolution process. When a large number of vortices appear at the impeller inlet, the outlet will also produce flow separation and wake phenomena, and a large number of vortices will block the flow path.

Figure 9 offers the radial velocity changes of the impeller outlet close to the front cover, the middle section, and the rear cover for one cycle, and the black dotted line indicates the position of the impeller blade, the white dotted line 

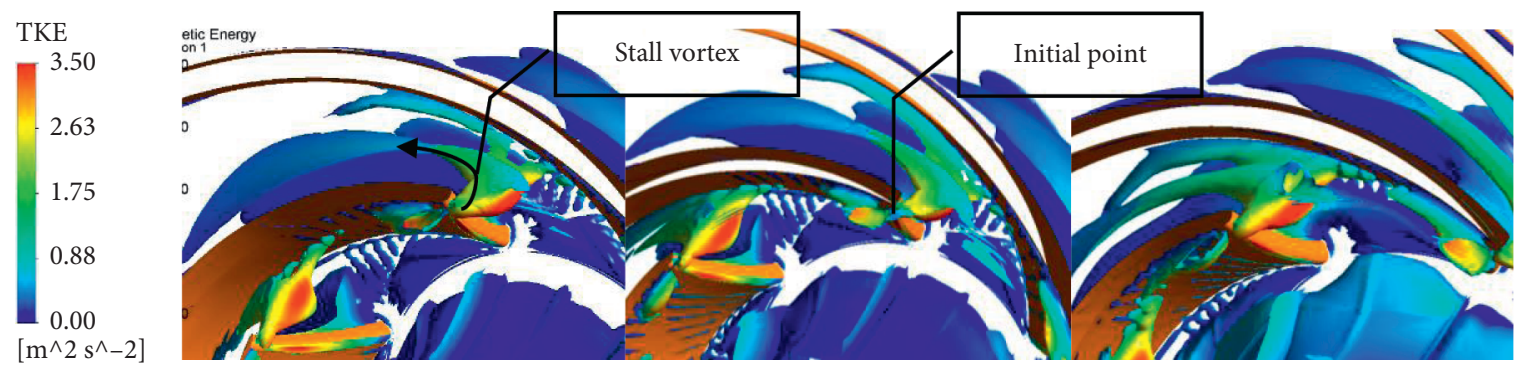

(a)

(b)

(c)

FIGURE 7: Vortex structure comparison of impeller inlet at different times at $0.4 \mathrm{Qd}$. (a) $t=360$. (b) $t=340$. (c) $t=320$.

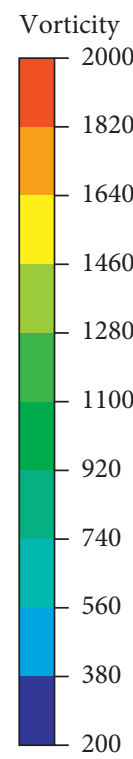

$\left[\mathrm{s}^{\wedge}-1\right]$

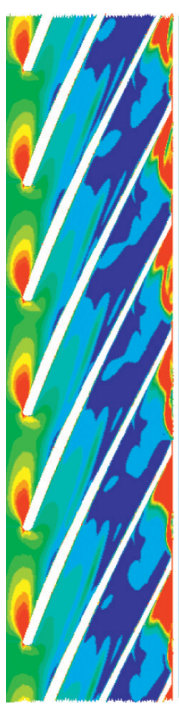

(a)

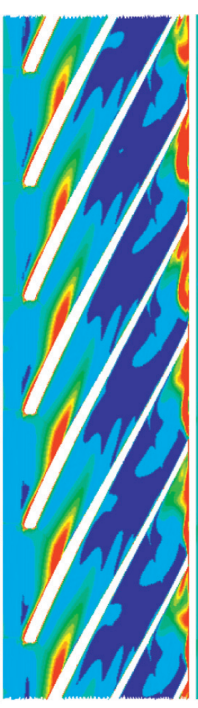

(b)

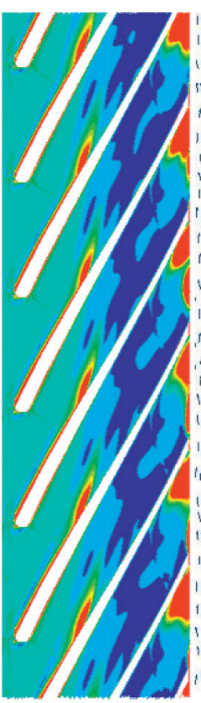

(c)

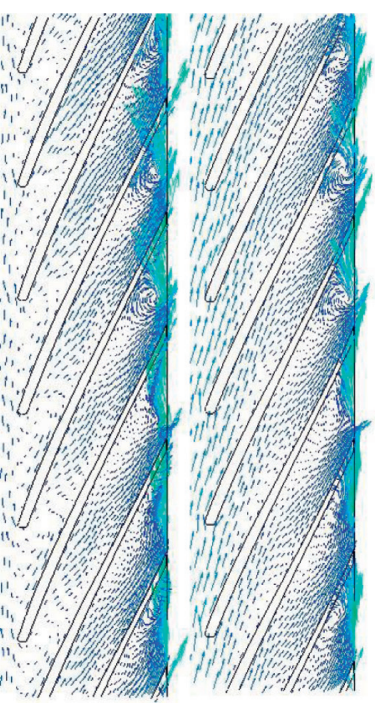

(d)



(f)

Figure 8: The distribution of vorticity and velocity vector. (a) $S P 0.85$. (b) $S P 0.5$. (c) $S P 0.15$. (d) $S P 0.85$. (e) $S P 0.5$. (f) $S P 0.15$

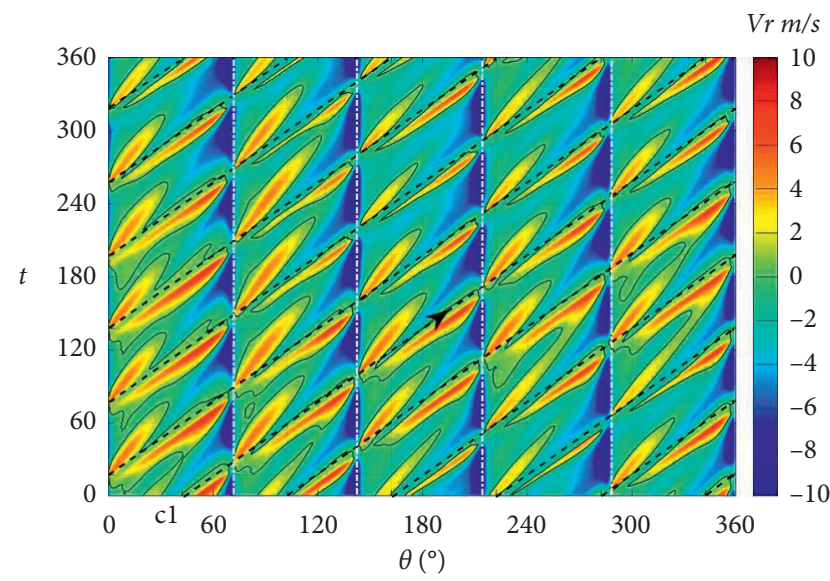

(a)

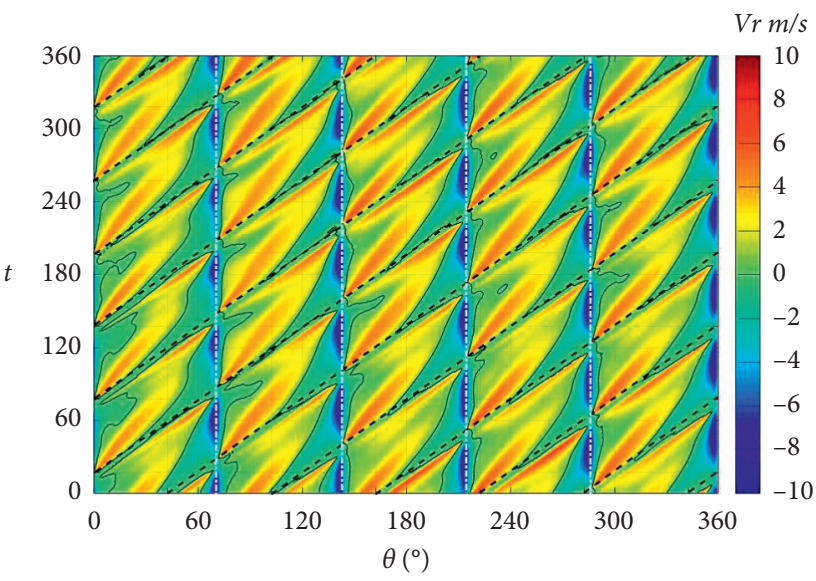

(b)

FIGURE 9: Continued. 


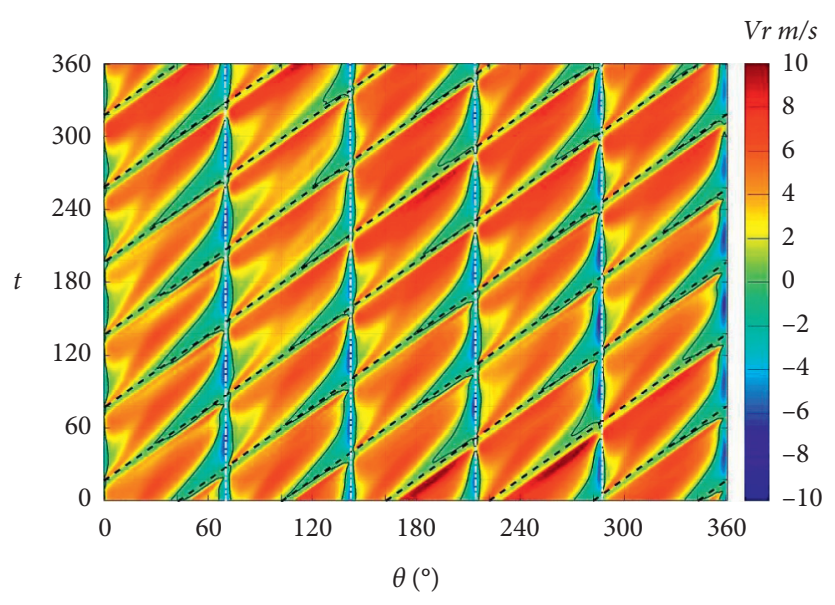

(c)

FIGURE 9: Radial velocity variation of impeller outlet in one cycle. (a) Span0.85. (b) Span0.5. (c) Span0.15.

indicates the position of the guide vane blade, the black line indicates that the radial velocity is 0 , and the black arrow indicates the direction of rotation of the impeller. Within an impeller rotation period, the distribution of radial velocity is at different blade heights, while the radial velocity of the impeller outlet is very similar in the distribution of each guide vane channel, which illustrates that the fluid can evenly enter the guide vane channel. By comparing the radial velocity of different guide vane channels, channel $C 1$ is slightly different from other channels. The positive radial velocity of cannel $C 1$ is higher than other channels near the front cover, and at the same time, the area of the negative radial velocity zone in cannel $C 1$ is greater than that of other channels around the middle section and the rear cover. Moreover, the outlet of the flow channel $C 1$ is the area where the volute tongue is located, indicating that the asymmetric structure of the volute has a strong influence on the flow field at the exit of the impeller.

By comparing the radial velocity of the impeller outlet at different times, it can be seen that the radial velocity of the impeller outlet presents obvious periodic fluctuation, which is caused by the BPF between the impeller and guide vane. At different blade heights, high radial velocity zones occur on all pressure surfaces of impeller blades, and a low radial velocity region appears in the blade thickness region between the blade pressure surface and the suction surface. Based on this analysis, it can be known that obvious jet-wake flow at blade trailing edge and its structure shows visible variation. When the impeller blade rotates from the suction side of the blade passage to the pressure side of the blade passage, the radial velocity of the jet flow area gradually increases; in contrast, the radial velocity of the wake flow area gradually decreases. Meanwhile, the radial velocity becomes negative when passing through the middle of the guide vane channel. The radial velocity of the jet flow area decreases sharply and becomes negative when the impeller blades and the guide vane blades intersect, while the radial velocity of the jet flow area and the wake flow area both increase instantly and become positive after passing the guide vane. Furthermore, with the impeller blades passing the guide vane blades, the rapid change of the radial velocity will lead to a large amount of energy loss and severe pressure fluctuations. Given the above analysis, a conclusion can be delivered that the phenomenon that guide vane blade cuts the jet-wake flow of impeller blade is the main reason for dynamic and static interference between impeller and guide vane. Also, the radial velocity of the impeller outlet near the front cover of the impeller is mostly less than 0 , and the radial velocity of the middle section of the impeller is greater than that near the front cover; its value reaches the maximum while in the position near rear cover. What is more, the large radial velocity gradient on the front and rear cover will result in high energy loss and reduce the efficiency of the centrifugal pump.

The boundary layer of the pressure surface of the impeller flow path separates, forming a vortex under small flow conditions as shown in Figure 10. Compared with the moment that the guide vane channel and the impeller channel overlap, the range of the vortex is significantly smaller when they intersect. But a large range of vortex will result in certain obstruction to impeller channels. By observing the axial surface streamlines diagram, the vortex will also be formed on the suction side of the guide vane channel, which will give rise to backflow at the front cover and increase the flow at the rear cover. This is the reason why the radial velocity of the front cover is less than 0 while at the rear cover is much greater than 0 as mentioned in the preamble. There is no large-scale vortex that can block the flow path on the pressure side of the guide vane channel, so the flow capacity near the pressure side of the guide vane channel is stronger and more stable than that on the suction side.

The monitoring points of the centrifugal pump are presented in Figure 11. Along the flow direction of the guide vane, they are named DP1, DP2, .., DP5 on the pressure side and DS1, DS2, ..., DS5 on the suction side. Besides, the GS1, GS2, and GS3 are the monitoring points around tongue volute. 



(a)

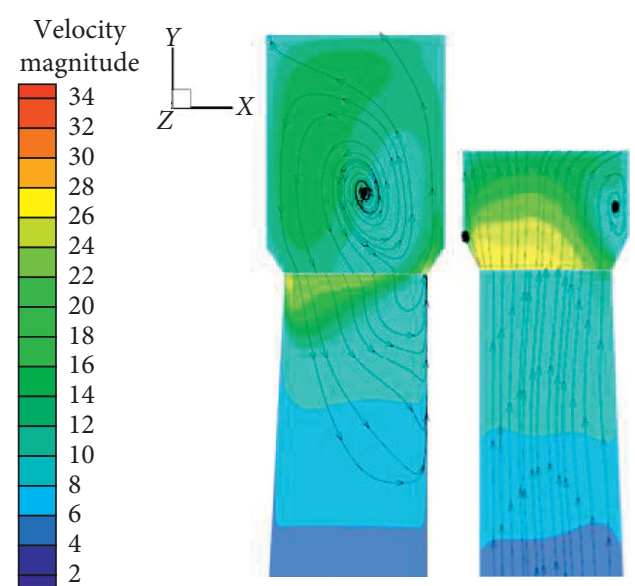

(b)

Figure 10: Midsection and axial surface streamline of impeller under part-load conditions.

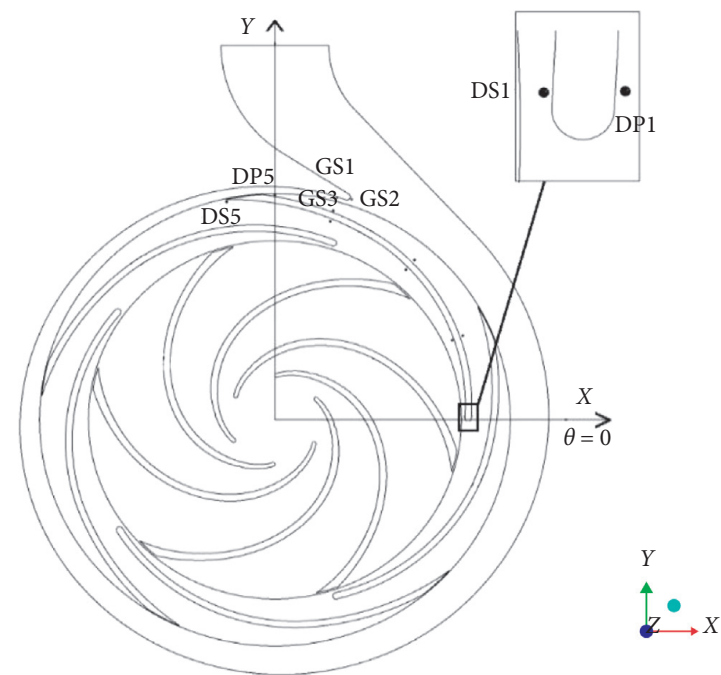

FIGURE 11: Monitoring points of the centrifugal pump.

Figure 12 depicts pressure pulsation at the monitoring points on both sides of the guide vane blade, where $a$ represents the figure of pressure pulsation frequency domain, $b$ presents the amplitude corresponding to the main frequency of each monitoring point, and fn is defined as the rotating frequency of impeller. It can be seen that the main frequency of the pressure pulsation in the guide vane is the leaf frequency, $\mathrm{fb}$, and its frequency multiplication. On the pressure surface of the guide vane, from the guide vane inlet to its outlet, the pressure pulsation amplitude of the leaf frequency and its frequency multiplication is gradually reduced. At the outlet of the guide vane, only the blade frequency has a higher amplitude, while other frequencies disappear. Correspondingly, in the suction surface of the guide vane, from the monitoring points DS1 to DS2, the amplitude of the leaf frequency first remains stable and then decreases rapidly. And the pressure fluctuation amplitude of the suction side of the guide vane is much higher than that of the pressure side, which illustrates that the dynamic and static interference are the strongest near the suction surface of the guide vane. Also, a low-frequency fluctuation of $0.2 \mathrm{fn}$ appears at the inlet of the guide vane, and the amplitude of the low-frequency fluctuation of the suction surface is also greater than that of the pressure surface, conducting that vortex with a frequency of $1 / 5$ of the rotation frequency of the impeller also occurs at the inlet of the guide vane, and most of that is transmitted downstream along the suction side of the guide vane.

In this study, the pressure coefficient is used to measure the pressure fluctuation, which is defined as

$$
C_{p}=\frac{p}{0.5 \rho u^{2}}
$$

where $p$ is the static pressure of the monitoring points, $\mathrm{Pa} ; \rho$ is density of fluid medium, $\mathrm{kg} / \mathrm{m}^{3}$; and $u$ is the circumferential velocity of impeller outlet, $\mathrm{m} / \mathrm{s}$.

Figure 13 shows the pressure fluctuation at the volute tongue and the amplitude at part-load frequency. Following the figure, information can be captured that the pressure 


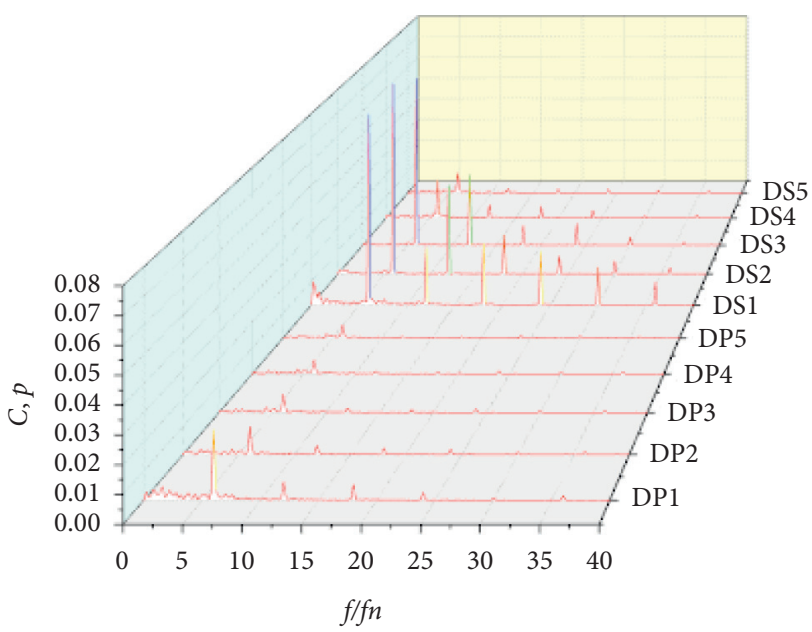

(a)



(b)

Figure 12: Pressure pulsation near guide vane blades. (a) Frequency domain. (b) Amplitude.
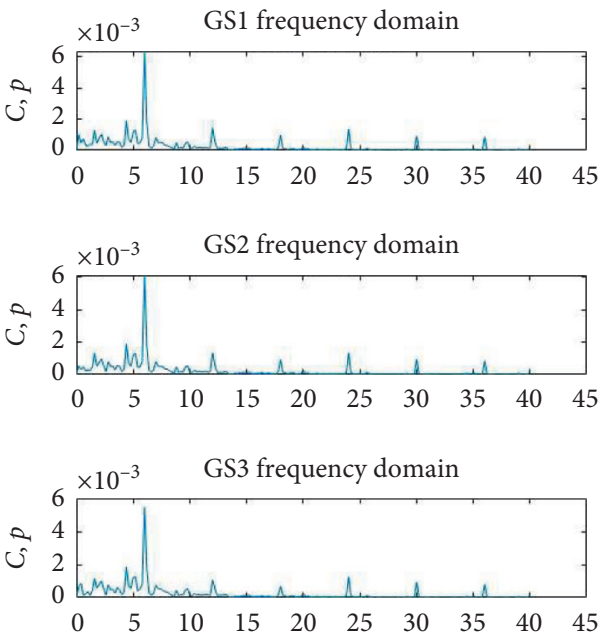

(a)

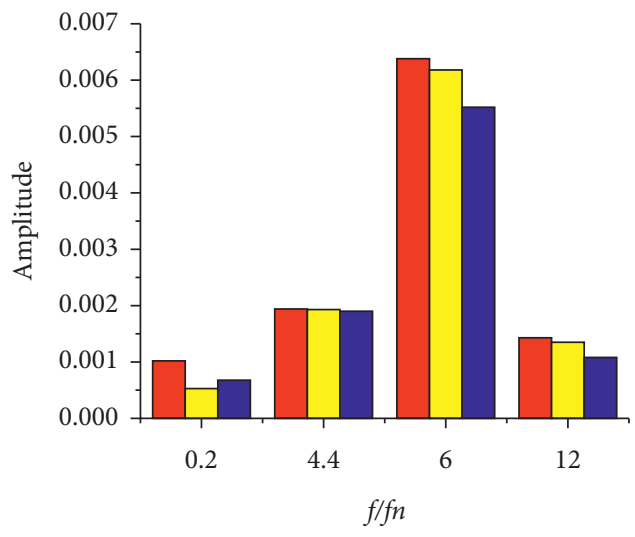

GS1

GS2

GS3

(b)

FIgUre 13: Pressure pulsation of tongue volute. (a) Frequency domain. (b) Amplitude.

fluctuations at the three monitoring points (GS1, GS2, GS3) are similar, the main frequency is the leaf frequency $6 f_{n}$, the second frequency is the leaf frequency multiplication, and complex low-frequency pressure pulsations appear. In comparison to the amplitude of the main frequency, when the frequency is $0.2 f_{n}$, monitoring point GS1 has the highest amplitude and GS2 has the lowest amplitude. When the frequency is $4.4 f_{n}$, the pressure pulsation amplitudes at the three monitoring points are almost the same. At the leaf frequency and leaf frequency multiplication, the pressure pulsation amplitude gradually decreases from the monitoring points GS1 to GS3. From the above analysis, the pressure pulsation intensity at the monitoring point GS1 is generally higher than that at GS2 and GS3. The pressure pulsation intensity on the inner side of the septum is also low due to the low flow velocity. Besides, the main frequency amplitude of the pressure pulsation in the volute tongue area is 0.006 , while that of the suction side inlet of the guide vane is 0.08 and the outlet is 0.01 , and that of the pressure side inlet is 0.025 and the outlet is 0.005 . Hence, the conclusion can be drawn that the region with the strongest RSI is the inlet region of the guide vane suction surface. It also occurs near the volute tongue but is lower due to the effect of the guide vane. 


\section{Conclusions}

In the present paper, by applying the DDES method to numerical simulation, the evolution of stall vortex in a centrifugal pump, the mechanism of dynamic and static interference between impeller and guide vane, and the analysis of pressure pulsation are revealed. Summarizing the above analysis, we can get the following conclusions.

The boundary layer at the inlet of the impeller blade breaks away when the centrifugal pump runs under the condition of part-load, leading to the formation of a vortex. The smaller the flow rate is, the larger the vortex is, resulting in the blockage of the impeller inlet, which leads to unnecessary energy loss and a reduction in the efficiency of the centrifugal pump. Also, under the design condition, the stall vortex at the inlet and outlet of the impeller disappears, and the vorticity in the whole impeller is less than $1000 \mathrm{~s}^{-1}$, forming the optimal flow dynamic structure. It suggests that the stall vortex caused by the rotating stall has a significant impact on the downstream flow structure.

The radial velocity distribution of the centrifugal pump impeller outlet presents obvious periodic fluctuations. The radial velocity of the impeller outlet gradually decreases from the rear cover plate to the front cover plate under the influence of the vortex, and backflow occurs at the front cover plate, which will result in high power loss and efficiency reduction due to large radial velocity gradient at front and back cover.

The influence of RSI on the centrifugal pump is mainly concentrated at the outlet of the impeller and the inlet of the guide vane. Among them, the phenomenon that the jet-wake flow impacts the guide vane with the rotation of the impeller is the main reason for the dynamic and static interference. Besides, the most intense area of RSI is in the zone of the inlet of the guide vane suction surface, while the intense are of RSI around the volute tongue is lower due to the presence of the guide vane. After introducing the DDES turbulence model, under the part-load condition $\left(Q=0.4 Q_{\text {des }}\right)$, the stall vortex structure can be clearly captured, and there are lowfrequency $\left(0.2 f_{n}\right)$ pressure fluctuations near the guide vane and the tongue.

\section{Data Availability}

The data used to support the findings of this study are available from the corresponding author upon request.

\section{Conflicts of Interest}

The authors declare that they have no conflicts of interest.

\section{Acknowledgments}

This work was supported by the National Natural Science Foundation of China (Grant no. 51809218), China Postdoctoral Science Foundation (Grant no. 2018M643744), and the Water Resources Science and Technology Projects in Shaanxi Province (Grant nos. 2017slkj-5 and 2018slkj-8).

\section{References}

[1] H. Fan and Y. Piao, "Cooling design of an aero-engine fuel centrifugal pump at shut-off," Advances in Mechanical Engineering, vol. 9, no. 6, 2017.

[2] D. Ni, M. Yang, N. Zhang, B. Gao, and Z. Li, "Unsteady flow structures and pressure pulsations in a nuclear reactor coolant pump with spherical casing," Journal of Fluids Engineering, vol. 139, no. 5, Article ID 051103, 2017.

[3] B. C. Good and K. B. Manning, "Computational modeling of the food and drug administration's benchmark centrifugal blood pump," Artificial Organs, vol. 44, no. 7, 2020.

[4] Z. Zou, F. Wang, Z. Yao, R. Tao, R. Xiao, and H. Li, "Impeller radial force evolution in a large double-suction centrifugal pump during startup at the shut-off condition," Nuclear Engineering and Design, vol. 310, pp. 410-417, 2016.

[5] Q. Li, X. Ma, P. Wu, S. Yang, B. Huang, and D. Wu, "Study on the transient characteristics of the centrifugal pump during the startup period with assisted valve," Processes, vol. 8, no. 10, p. 1241, 2020.

[6] L. Yun, L. Bin, F. Jie, Z. Rongsheng, and F. Qiang, "Research on the transient hydraulic characteristics of multistage centrifugal pump during start-up process," Frontiers in Energy Research, vol. 8, 2020.

[7] Q. Si, B. Wang, J. Yuan, K. Huang, G Lin, and C Wang, "Numerical and experimental investigation on radiated noise characteristics of the multistage centrifugal pump," Processes, vol. 7, no. 11, p. 793, 2019.

[8] H. Liu, Z. Cheng, Z. Ge, L. Dong, and C. Dai, "Collaborative improvement of efficiency and noise of bionic vane centrifugal pump based on multi-objective optimization," Advances in Mechanical Engineering, vol. 13, no. 2, 2021.

[9] C. Dai, C. Guo, Y. Chen, L. Dong, and H. Liu, "Analysis of the influence of different bionic structures on the noise reduction performance of the centrifugal pump," Sensors, vol. 21, no. 3, p. 886, 2021.

[10] J. M. C. Cubas, H. Stel, E. M. Ofuchi, M. A. M. Neto, and R. E. M. Morales, "Visualization of two-phase gas-liquid flow in a radial centrifugal pump with a vaned diffuser," Journal of Petroleum Science and Engineering, vol. 187, Article ID 106848, 2020.

[11] P. Guangjie, H. Xin, Z. Ling, Z. Guoxin, and Z. Hong, "Solidliquid two-phase flow and wear analysis in a large-scale centrifugal slurry pump," Engineering Failure Analysis, vol. 114, Article ID 104602, 2020.

[12] W. Cao, W. Li, L. Ji, W. Shi, Z. Lu, and R. K. Agarwal, "Research of transient rotor-stator interaction effect in a mixed-flow pump under part-load conditions," Journal of the Brazilian Society of Mechanical Sciences and Engineering, vol. 42, no. 1, pp. 1-15, 2020.

[13] C. G. Rodriguez, E. Egusquiza, and I. F. Santos, "Frequencies in the vibration induced by the rotor stator interaction in a centrifugal pump turbine," Journal of Fluids Engineering, vol. 129, no. 11, pp. 1428-1435, 2007.

[14] C. Issa, E. Sami, K. Hatem, and A. Mohsen, "The effects of the rotor-stator interaction on unsteady pressure pulsation and radial force in a centrifugal pump," Journal of Hydrodynamics, vol. 30, no. 4, pp. 672-681, 2018.

[15] D. Y. Li, R. Z. Gong, H. J. Wang, X. Z. Wei, D. Q. Qin, and Z. S. Liu, "Analysis of rotor-stator interaction in turbine mode of a pump-turbine model," Journal of Applied Fluid Mechanics, vol. 9, no. 5, pp. 2559-2568, 2016.

[16] F. Nobumichi, H. Shotaro, and O. Yutaka, "Unsteady behavior of leading-edge vortex and diffuser stall in a centrifugal 
compressor with vaned diffuser," Journal of Thermal Science, vol. 25, no. 1, pp. 13-21, 2016.

[17] L. Fu, C. Hu, C. Yang, W. Bao, and M. Zhou, "Vortex trajectory prediction and mode analysis of compressor stall with strong non-uniformity," Aerospace Science and Technology, vol. 105, Article ID 106031, 2020.

[18] K. Kan, Y. Zheng, Y. Chen, Z. S. Xie, G. Yang, and C. Yang, "Numerical study on the internal flow characteristics of an axial-flow pump under stall conditions," Journal of $\mathrm{Me}$ chanical Science and Technology, vol. 32, no. 10, pp. 46834695, 2018.

[19] W. Li, L. Ji, E. Li, W. Shi, R. Agarwal, and L. Zhou, "Numerical investigation of energy loss mechanism of mixed-flow pump under stall condition," Renewable Energy, vol. 167, no. 9, 2020.

[20] N. Ashton, R. Prosser, and A. Revell, "A hybrid numerical scheme for a new formulation of delayed detached-eddy simulation (DDES) based on elliptic relaxation," Journal of Physics: Conference Series, vol. 318, no. 4, Article ID 042043, 2011.

[21] J. Li, J. Hu, and C. Zhang, "Investigation of vortical structures and turbulence characteristics in corner separation in an axial compressor stator using DDES," Energies, vol. 13, no. 9, p. $2123,2020$.

[22] D. Lin, X. Su and X. Yuan, DDES analysis of the wake vortex related unsteadiness and losses in the environment of a highpressure turbine stage," Journal of Turbomachinery, vol. 20, p. 18, 2018.

[23] N. Zhang, X. Liu, B. Gao, and B. Xia, "DDES analysis of the unsteady wake flow and its evolution of a centrifugal pump," Renewable Energy, vol. 141, pp. 570-582, 2019.

[24] E. Abdolahnejad, M. Moghimi, and S. Derakhshan, "Experimental and numerical investigation of slip factor reduction in centrifugal slurry pump," Journal of the Brazilian Society of Mechanical Sciences and Engineering, vol. 43, no. 4, p. 179, 2021.

[25] Y. Y. Huan, Y. Y. Liu, X. J. Li et al., "Experimental and numerical investigations of cavitation evolution in a highspeed centrifugal pump with inducer," Journal of Hydrodynamics, vol. 33, no. 1, pp. 140-149, 2021.

[26] Y. Ma, M. Zhang, and H. Luo, "Numerical and experimental studies of gas-liquid flow and pressure drop in multiphase pump valves," Science Progress, vol. 103, no. 3, 2020. 